\title{
Analysis on the Effect of Chinese Medical Reform Policy on Medical Listed Companies -- Empirical Analysis on Listed Companies' Stocks Returns
}

\author{
Xiaoqian $\mathrm{Fu}^{1}$ \\ ${ }^{1}$ Graduate School of Health and Welfare Science, International University of Health and Welfare, Tokyo, Japan \\ Correspondence: Xiaoqian Fu, Graduate School of Health and Welfare Science, International University of Health \\ and Welfare, Tower-Aoyama Ittyome, Minami Aoyama 1-3-3, Minato-ku, Tokyo, Japan. Tel: 81-3-6406-8621.
}

Received: March 6, 2018

Accepted: April 4, 2018

Online Published: April 19, 2018

doi:10.5430/jms.v9n2p20

URL: https://doi.org/10.5430/jms.v9n2p20

\begin{abstract}
This paper studies the stock market reaction of medical reform policies to examine policies' effect on the listed companies which invested in hospital. This paper applies the method of Event Study, finding out that the announcement of the new round of medical and health systemic reform in 2009, the key work for medical and health systemic reform and its detailed rules of implementation in 2010, and the setting of several specific goals to develop the private hospitals run by civilians in 2012, have taken increases of listed companies' stocks returns (rate of return) by $2.95 \%, 4.64 \%$ and $4.92 \%$ separately. That means the whole market value rose by almost 55 billion, 128 billion, and 131 billion of RMB respectively. The empirical analysis results show that share price's return rate of the listed companies which invested in hospital are significantly associated with industrial planning and supporting policies launched by the government. That is to say, Chinese government's policy which began to encourage and guide civilian capital to develop the medical industry stimulated the medical and health industry effectively and significantly.
\end{abstract}

Keywords: medical industry, event study, abnormal return, listed companies

\section{Introduction}

Government supporting policies and planning are important for an industry to obtain and sustain healthy and stable development. In particular, government directional policies have tremendous effect on medical industry considering its specialty and Chinese development environment. (Cai, 2014) For instance, Chinese government had issued new medical and health reform policies in year 2009 which guide civilian capitals to invest and help developing medical and health industry. These policies now produced effects on that listed companies had started to invest in hospitals.(Kong, Liu, Li, \& Wu, 2013) To better understand the effect of Chinese medical policy on medical listed companies from empirical analysis point of view, it is meaningful to analyze the reaction of these medical listed companies to the change of policies.

The establishment of Shanghai and Shenzhen Securities Exchange and joint-stock reform of state-owned companies made China's securities market developing rapidly in market capacity, market transactions varieties, means of transactions, and other aspects of the regulatory system.(Zhang, Liu, \& Hu, 2002) On the other hand, there are still many problems in the process of this rapid development. For instance, market response to policies and regulations is one of the theoretical issues of great concern. (Tang, 2016) Besides, Chinese policy permits hospital management companies to be listed, which is a premise for this work. But in many countries such as Japan, hospital management companies are not allowed to be listed, which lead to the lack of necessary market data.

The aim of this study is to analyse how much the relevant major policies influenced the corporate value of the listed companies which invested in hospitals in China's securities markets, by measuring whether the promulgation of related industrial policies impacted the listed companies' stocks returns. If the stock prices do respond to new information, not only will the effectiveness of the relevant policies be verified, but also a rational marketplace will be reflected. Accordingly, this study can make policy recommendation to the government; support investors with the basis for stock market investment; strengthen the confidence of investment; and provide listed companies with the basis to generate business strategy. 


\section{Literature Review}

Many studies have analyzed how new information resulting from exogenous changes to political platforms and legislation can have a direct impact on stock prices. Binder (1985) applied event study methodology to analyze multiple regulations and policies for the United States. Dnes, Kodwani, Seaton, \& Wood (1998) verified the reactions to British policy institution by the corporate value of electric power companies. Kamae and Tetsuka (2000) studied how the implementation of two regulatory policies issued by the Japanese government affected the 12 major private railroad companies. It was concluded that the two regulatory policies had a significant positive and continuing effect on the stock prices of railroad companies.

In China, some scholars had studied governmental policies for the promotion of improved ROI (return of investment) in agriculture and high technology. Zhang, Ren, Jia, \& Yu (2013) argued that national intervention policies on real estate have relatively strong impacts in the short term, but their long-term effects are limited. They may only play a fine tuning role in regulating the market instead of determining the overall market tendencies, whereas government intervention targeting the supply side is able to create continuing long-term effects.

All of the researches above have used the event study methodology which also applied in this research. The seminal work of Fama, Fisher, Jensen, \& Roll (1969) established the event study method to measure whether the announcement of new information has a statistically significant effect on a firm's stock market value.

Concerning the medical related policies, Ababneh and Tang (2013) investigated the effect of the U.S. Supreme Court's decision to uphold president Obama's health care reform on the stocks of impacted firms, and found that the law had different effect on health insurance companies, drug makers and hospitals. And Hartley $(2012)^{11)}$ created an event study that measured the impact of the law by observing health care firm stocks in the S\&P 500 in 2012. Due to the reasons such as data access, few papers could be found in Chinese market. Zhang (2010) evaluated the impacts of drug price reduction policies between 1997 and 2007 in China by event study method, and concluded that the price reduction intervention in the first month of implementation has the most significantly negative effect on medical market prices but the duration of reduction intervention effect is short.

Because of the government policies, China's listed companies started to be allowed to invest in hospitals from 2009. Therefore, limited data can be used, and to the best of author's knowledge, there is little research on the empirical analysis of this subject.

\section{Method}

Event Study is to analyze the impact of a major event on a particular object of concern. At present, the influential factors of stock price volatility are more widely studied in the financial field. One of them is major events such as the promulgation of major national policies. Due to the effectiveness of the policy, it is often difficult to play a substantive role in the core elements of business performance in the short term. Therefore, this paper studies the impact of policy on the stock price of Chinese medical companies in terms of industrial capital, and examines the effectiveness of government policies.

\subsection{Selection of Events}

Within the development period of medical and health industry the year 2009 has marked the beginning of a new round of medical and health system reform in the Chinese market. Relevant industrial planning and supporting policies, launched in 2009 by the government, are guiding the industry to enter a new chapter of its development, i.e., the combination of government leadership and market mechanisms. More importantly, it also means civilian capitals are encouraged to invest in medical and health industry. For the listed companies invested in hospitals, this is a positive event that can increase market acceptance.

The content of medical and health policies promulgated by Chinese government during the period from January, 2009 to May, 2013 was analyzed, and three years important directional policies as the events were identified. These policies are briefed and listed as following:

First, Guidelines on Deepening the Reform of Medical and Health System issued by the CPC(Communist Party of China) Central Committee and the State Council on March 17, 2009, which opened the prelude to the new medical and health reform.

Second, Five Key Reforms of Medical and Health System and Main Work Arrangement in 2010 issued by China's State Council on April 6, 2010, identifying the key work for medical and health system reform and its detailed rules of implementation in 2010, which further improved the feasibility of the reform policies in 2009. The same effect can be expected in the securities exchange market.

Third, The Notification on the Issuing of the Planning and Implementation Solution for Deepening Medical and 
Health System Reform during the 12th Five-year Plan issued by China's State Council on March 14, 2012, in which it has set several specific goals, such as the proportions (20\%) of the number of private hospital wards and service amounts against the total quantities by the end of 2015. This is also a positive event for the stock return of the companies invested in hospitals.

These three policies represent significant events that happened in the medical industry in recent years. The medical reform in 2011 focused on public hospital, which has less relationship with the object companies in this research, thus it was not selected as the object event of this research.

\subsection{Selection of Companies}

In this study, the hospital administrative companies and those other listed companies with investments in hospitals in the Shanghai and Shenzhen securities exchanges were selected, and the dates of investment behaviors by referring to open information such as corporate announcements were identified. The listed companies which invested in hospitals before the event occurrence date were selected as samples to evaluate the influence of policies on the listed companies. There were 10 companies that were chosen as samples in 2009, 11 in 2010, and 19 in 2012.

\subsection{Selection of Models}

As for an event study assess the effect of an event on the value of a company, it was applied to test the effect of policies in this study. For the approach of event study in this paper, a total of 10 days (a total of 11 days plus the day of the promulgation of policy) before and after the occurrence of the event is selected as the "event window", with the situation of premature information leakage considered. (Ababneh, \& Tang, 2013) The day of announcement was $\mathrm{T}_{0}$. In this study, $\mathrm{T}_{0}$ was March 17, 2009, April 6, 2010, and March 14, 2012 respectively. The period from $\mathrm{t}_{-115}$ to $\mathrm{t}_{-15}$ (100 days) was selected as the "estimation window". (Seiler, 2004) The daily data from estimation window were used to calculate abnormal returns during event window.

Next, a market model was utilized to measure normal performance, which reduced the variance of the abnormal return by removing the portion of the return that is related to variation in the market's return. Then, Capital Asset Pricing Model (CAPM) was applied as economic models which can be cast as restrictions on the statistical models to provide more constrained normal return models. The null hypothesis was conducted that the given event has no impact on the behavior of the returns.

To measure the effects on financial markets, there are two common methods: abnormal return (AR) and cumulative abnormal return (CAR). This study measured the effects of new governmental policies on corporate value by applying the AR in the event window, and the overall effect during a certain period of time by applying the CAR. The abnormal return observations should be aggregated in order to draw overall inferences for the event of interest. "The concept of a cumulative abnormal return is necessary to accommodate a multiple period event window." (Ababneh, \& Tang, 2013) The event window used for analyzing AR includes the period from $T_{-5}$ to $T_{5}$, which means from five days before to five days after the promulgation of the policies. To compare the conspicuousness of the policies' effect on stock prices in different time periods, the average accumulative abnormal returns on other time periods within the event window are analyzed such as the period from $T_{-5}$ to $T_{-1}$ and $T_{0}$ to $T_{5}$ etc., not only for drawing overall inferences on event window but also for more information such as comparing results. Mackinlay (1997) stated the necessity of analyzing accumulative abnormal returns. During the analytical process, if there are cases of trade suspension or holidays, the transaction data of the following trading day is applied for analyzing.

The calculation procedures are listed below:

1) When calculating the company's daily return and the market portfolio's return, the basic hypothesis is that the news of equity price change is yet to be declared:

$$
\begin{aligned}
& R_{i t}=\left(P_{i t}-P_{i t-1}\right) / P_{i t-1} \\
& R_{m t}=\left(I_{i t}-I_{i t-1}\right) / I_{i t-1}
\end{aligned}
$$

In this equation, $\mathrm{P}_{\mathrm{it}}$ represents the closing price of the share of Company $i$ at day $t$, and $\mathrm{I}_{\mathrm{it}}$ is the closing index price of the CSI 300 index(a composite index of Shanghai and Shenzhen securities exchanges) at day $t$, whereas $\mathrm{R}_{\mathrm{it}}$ and $\mathrm{R}_{\mathrm{mt}}$ are the daily returns on security $\mathrm{i}$ and CSI 300 index for day t.

2) When calculating abnormal returns, cumulative abnormal returns and their mean values for each company, adopted the market model with the following estimation:

$$
R_{i t}=\alpha_{i}+\beta_{i} R_{m t}+\varepsilon_{i t}
$$

Where $\alpha_{\mathrm{i}}$ and $\beta_{\mathrm{i}}$ are parameters estimated from the ordinary least squares (OLS) regression of security i's daily returns on the CSI 300 index for day t. 
When we have the following assumptions: $\mathrm{E}\left[\varepsilon_{\mathrm{it}}\right]=0$ and $\operatorname{Var}\left[\varepsilon_{\mathrm{it}}\right]=\sigma_{\mathrm{it}}{ }^{2}$, it can be inferred that the normal returns which are defined as the expected returns without conditioning on the event taking place for each company at day $t$ is:

$$
E[R i t \mid R m t]=\alpha i+\beta i R m
$$

Abnormal return for firm $i$ and event date $t$ in the event window based on the CAPM model is:

$$
\text { ARit }=\text { Rit }-E[R i t \mid R m t] \sim N\left(0, \sigma_{i t}{ }^{2}\right)
$$

During the given period of day $k$, the cumulated abnormal return is:

$$
\operatorname{CARi}(t, t+K)=\sum_{k=0}^{k} A R_{i, t+k}
$$

Since there are many listed companies among the samples, this study applied the mean value of AR and CAR to perform hypothesis testing. Under the null hypothesis, $\mathrm{H}_{0}$, the distribution of the sample average abnormal return and average cumulative abnormal return of a given observation in the event window are:

$$
\begin{gathered}
\overline{A R}_{t}=\frac{1}{N} \sum_{n=1}^{N} A R_{n t} \sim N\left(0, \frac{1}{N^{2}} \sum_{n=1}^{N} \sigma_{n t}^{2}\right) t \\
\overline{C A R(t, t+K)}=\frac{1}{N} \sum_{n=1}^{N} C A R_{n}(t, t+K) \sim N\left(0, \frac{1}{N^{2}} \sum_{n=1}^{N} \sigma^{2}\left(C_{n}(t, t+K)\right)\right)
\end{gathered}
$$

3) Conducted one-sample t-test using SPSS (IBM, NYC). Assuming that no values of $A R_{\text {it }}$ have a linear relationship during the entire period where the event occurs, $\operatorname{CAR}_{\mathrm{i}}(\mathrm{t}, \mathrm{t}+\mathrm{K})$ is subject to the distribution $\mathrm{N}\left(0, \sigma^{2}\left(\mathrm{CAR}_{\mathrm{i}}(\mathrm{t}, \mathrm{t}+\mathrm{K})\right)\right.$ :

$$
\text { CARi }(t, t+K) \sim N(0, \sigma 2(C A R i(t, t+K))
$$

Where $\sigma^{2}\left(\mathrm{CAR}_{\mathrm{i}}(\mathrm{t}, \mathrm{t}+\mathrm{K})\right)=(\mathrm{K}+1) \sigma_{\mathrm{it}}{ }^{2}$. Under the null hypothesis, $\mathrm{CAR}_{\mathrm{i}}(\mathrm{t}, \mathrm{t}+\mathrm{K})=0$, then tests of the null hypothesis can be conducted.

\section{Results}

Table 1 shows the numbers and market values of samples. The number of sample companies and the sum of their total market values of the day 5 days before each event was shown in Table 1, in which the market values equals the stock price multiplied by total shares.

Table 1. Market value statistical list of listed companies which invest in hospital

\begin{tabular}{|c|c|c|c|c|c|c|}
\hline Time $\mathrm{t}$ & $\begin{array}{l}\text { Mar. } 2009 \\
\overline{A R}(\%)\end{array}$ & $\overline{C A R}(\%)$ & $\begin{array}{l}\text { Apr. } 2010 \\
\overline{A R}(\%)\end{array}$ & $\overline{C A R}(\%)$ & $\begin{array}{l}\text { Mar. } 2012 \\
\overline{A R}(\%)\end{array}$ & $C A R(\%)$ \\
\hline-5 & 0.88 & 0.88 & -1.06 & -1.06 & -0.12 & -0.12 \\
\hline-4 & -0.11 & 0.76 & 0.15 & -0.91 & 0.56 & 0.44 \\
\hline-3 & 0.67 & 1.44 & $0.69 *$ & -0.22 & $1.11 *$ & 1.55 \\
\hline-2 & -1.22 & 0.22 & -0.08 & -0.30 & $1.77 *$ & 3.32 \\
\hline-1 & $1.09 *$ & 1.31 & $-0.59 *$ & -0.89 & 0.24 & 3.56 \\
\hline 0 & $2.28 *$ & 3.59 & $0.99 * * *$ & 0.10 & $-1.46 * * *$ & 2.10 \\
\hline 1 & 0.12 & 3.71 & 0.54 & 0.64 & 1.11 & 3.21 \\
\hline 2 & -0.43 & 3.28 & $1.50 * *$ & 2.15 & $2.04 * * *$ & 5.25 \\
\hline 3 & $-1.76 *$ & 1.53 & $1.68 * * *$ & 3.82 & $1.65 *$ & 6.89 \\
\hline 4 & 0.91 & 2.43 & 2.51 & 6.33 & -1.83 & 5.07 \\
\hline 5 & 0.52 & 2.95 & -1.69 & 4.64 & -0.14 & 4.92 \\
\hline
\end{tabular}

\begin{tabular}{llll}
\hline date & $2009 / 3 / 10$ & $2010 / 3 / 29$ & $2012 / 3 / 7$ \\
\hline Company Count & 10 & 11 & 19 \\
Total Value(RMB/Billion) & 187.84 & 277.25 & 266.61 \\
\hline
\end{tabular}

The variables of $\overline{\mathrm{AR}}$ and $\overline{\mathrm{CAR}}$ are calculated as follows: Table 2 presents the average abnormal return $(\overline{\mathrm{AR}})$ value caused by the three events; Table 3 presents the average accumulative abnormal return ( $\overline{\mathrm{CAR}})$ and the value of the corresponding $\mathrm{T}$ statistic during six periods for the times when the three events occurred.

Table 2. Average AR of listed companies which invested in hospitals under the new governmental policies

$*=\mathrm{T}$ statistic significant at $10 \% ; * *=\mathrm{T}$ statistic significant at $5 \% ; * * *=\mathrm{T}$ statistic significant at $1 \%$ 
Table 3. Average CAR of listed companies which invested in hospitals under the new governmental policies

\begin{tabular}{lllllll}
\hline & Mar. 2009 & & Apr. 2010 & Mar. 2012 & \\
Time t & $\overline{C A R}(\%)$ & T Value & $\overline{C A R}(\%)$ & T Value & $\overline{C A R}(\%)$ & T Value \\
\hline$[-5,5]$ & 2.95 & 1.44 & 4.64 & $3.79^{* * *}$ & 4.92 & $3.36^{* * *}$ \\
{$[-5,-1]$} & 1.31 & 1.98 & -0.89 & 0.13 & 3.56 & $2.58^{* *}$ \\
{$[-4,-1]$} & 0.43 & 1.96 & 0.17 & 1.84 & 3.68 & $2.73^{* *}$ \\
{$[-3,-1]$} & 0.55 & 2.53 & 0.02 & 2.74 & 3.12 & $1.90^{*}$ \\
{$[-2,-1]$} & -0.13 & 2.10 & -0.67 & 0.86 & 2.01 & 0.67 \\
{$[-1,-1]$} & 1.09 & $2.81^{*}$ & -0.59 & $1.13^{*}$ & 0.24 & $-2.78^{* *}$ \\
{$[0,1]$} & 2.40 & $2.50^{* *}$ & 1.53 & $3.16^{* * *}$ & -0.35 & -0.34 \\
{$[0,2]$} & 1.97 & 1.38 & 3.04 & $3.41^{* * *}$ & 1.69 & 1.58 \\
{$[0,3]$} & 0.22 & 0.29 & 4.71 & $5.06^{* * *}$ & 3.33 & $2.71^{* *}$ \\
{$[0,4]$} & 1.12 & 0.81 & 7.22 & $7.55^{* * *}$ & 1.51 & 1.27 \\
{$[0,5]$} & 1.64 & 0.93 & 5.53 & $5.99^{* * *}$ & 1.36 & 1.15 \\
\hline
\end{tabular}

$*=\mathrm{T}$ statistic significant at $10 \% ; * *=\mathrm{T}$ statistic significant at $5 \% ; * * *=\mathrm{T}$ statistic significant at $1 \%$.

From Table 2 and Table 3, it can be inferred that on March 17, 2009, the day when Guidelines on Deepening the Reform of Medical and Health System was issued, the average abnormal return reached 2.28\%, with a confidence level of $10 \%$. The average cumulative abnormal return of the time periods $\left(\mathrm{T}_{-1}, \mathrm{~T}_{-1}\right)$ and $\left(\mathrm{T}_{0}, \mathrm{~T}_{1}\right)$ were $1.09 \%$, and $2.4 \%$ which had confidence levels of $10 \%$ and $5 \%$. Compared to other time period, these values have a better confidence level. Calculated by the market value of RMB 187.8 billion on the day $\mathrm{T}_{-5}$, the market value of the sample industry had achieved an increase of RMB 4.5 billion within the two days of $\left(\mathrm{T}_{0}, \mathrm{~T}_{-1}\right)$.

In April of 2010, the General Office of the State Council declared the key work of medical and health system reforms and provided implementation details. On the day of issuing, the average abnormal return was $0.99 \%$, with a confidence level of $1 \%$, and such increasing tendency persisted on the $2^{\text {nd }}$ and $3^{\text {rd }}$ days after the event with confidence levels of $5 \%$ and $1 \%$ respectively. The average cumulative abnormal returns of every period after the day of promulgation, $\left(\mathrm{T}_{0}, \mathrm{~T}_{1}\right),\left(\mathrm{T}_{0}, \mathrm{~T}_{2}\right),\left(\mathrm{T}_{0}, \mathrm{~T}_{3}\right),\left(\mathrm{T}_{0}, \mathrm{~T}_{4}\right)$ and $\left(\mathrm{T}_{0}, \mathrm{~T}_{5}\right)$, was statistically significant with confidence levels of $1 \%$, and reached a peak value of $6.33 \%$ on the period from $\mathrm{T}_{-5}$ to $\mathrm{T}_{4}$.

On the two days of $\mathrm{T}_{-3}$ and $\mathrm{T}_{-2}$ before the release of the notification on further deepening of reforms by the State Council on March 2012, AR showed significant growth with a confidence level of 10\%. On the day of issuing, the value showed an obvious drop, and it recovered to significantly increase on the $2^{\text {nd }}$ and the $3^{\text {rd }}$ days after the event accompanied by market volatility. The statistically significant increase of CAR in the four periods $\left(\mathrm{T}_{-5}, \mathrm{~T}_{-1}\right),\left(\mathrm{T}_{-4}, \mathrm{~T}_{-1}\right)$, $\left(\mathrm{T}_{-3}, \mathrm{~T}_{-1}\right),\left(\mathrm{T}_{-1}, \mathrm{~T}_{-1}\right),\left(\mathrm{T}_{0}, \mathrm{~T}_{3}\right)$ and $\left(\mathrm{T}_{-5}, \mathrm{~T}_{5}\right)$ constituted an increasing tendency with confidence levels of $5 \%$, $5 \%, 10 \%, 5 \%, 5 \%$ and $1 \%$ respectively.

The CARs caused by the positive policies announced in April 2010 and March 2012 are 4.64\% and 4.92\% respectively with confidence levels of $1 \%$. According to the total market value of the listed companies in the medical and health industry, the two policies have helped increase the total value of the listed companies by RMB 12.86 billion and RMB 13.12 billion respectively.

Figure 1 showed the effect of policy promulgation on average CAR of listed companies which invested in hospitals under the new governmental policies of 2009, 2010 and 2012. The average CAR plots shows that to some extent the market gradually learns about the forthcoming announcement of policies. 


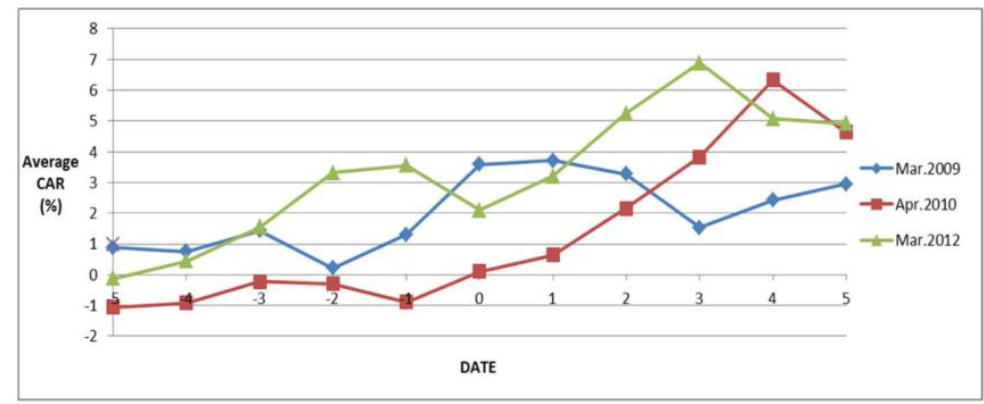

Figure 1. The Effect of policy promulgation on average CAR of listed companies which invested in hospitals under the new governmental policies

\section{Discussion}

On the basis of empirical analysis's result of AR in table 2, the three selected policies had statistically significant impact on the sample companies in 3 days (policy in 2009) during the event window. Particularly, the average accumulative abnormal returns caused by policies issued in 2010 and 2012 during the whole event window $\left(\mathrm{T}_{-5}, \mathrm{~T}_{5}\right.$ ), were statistically significant positive numbers of $4.64 \%$ and $4.92 \%$. That means the issuing of policies brought increases of $4.64 \%$ and $4.92 \%$ compared to no policy announced in event window. Therefore, it was concluded that Chinese medical reform policies affected medical listed companies' market value. The respective investigations of three policies are as follows:

The favorable news regarding the new medical and health system reforms in 2009 has contributed to notable growth of the abnormal returns for the companies in the industry even five days prior to the policy being announced. There was also an abnormal increase by $2.28 \%$ on the day of issuing. Five days before and after the issuing of the policy, the news indirectly contributed to the increase of market value by RMB187.8 billion for listed companies. This suggested that reform policies by related government departments have brought positive effects to these companies and boosted the interests of investors. However, through the analyses on the announcement of the two ensuing policies, the conspicuousness of AR brought by the first policy issuance is not as obvious as in the following ones. One possible reason may be that popular understanding and confidence toward the new medical and health system reforms were still in a nascent phase. Thus, people held an observing attitude (wait-and-see) towards the development trends of the reforms. This can also be inferred from the lack of conspicuousness of the AR increase during the period from $\mathrm{T}_{0}$ to $\mathrm{T}_{5}$.

In 2010, on the very day of the announcement of the implementation details, for example, eligible private hospitals will be included in the scope of medical insurance and enjoy the same tax and price policy as public medical institutions, the average abnormal return was $0.99 \%$, with a confidence level of $1 \%$, saving that the increase persisted on the $2^{\text {nd }}$ and $3^{\text {rd }}$ days after the event with confidence levels of 5\% and $1 \%$. This suggested that the confidence of the market was increasingly on the rise and featured sensitive responsiveness after about one year of corporate development momentum. Also based on the conspicuousness of the statistics on the growth of average CAR during five periods, namely from $T_{0}$ to $T_{1}, T_{0}$ to $T_{2}, T_{0}$ to $T_{3}, T_{0}$ to $T_{4}$, and $T_{0}$ to $T_{5}$, it was found that the market demonstrated relative sensitivity. Additionally, the average CAR's peak value (7.22\%) of this study on $\left(\mathrm{T}_{0}, \mathrm{~T}_{4}\right)$, indicates that the issuing of the implementation details for system reform has spurred an increase in stock return. Concerning the slight drop on the day of $\mathrm{T}_{5}$, it was considered that a revision of the previous strong market optimism demonstrates the market caution.

In year 2012, the government continued to set specific goals, such as the proportions of numbers of new wards and service amounts against the total quantities in private hospitals. This convinced the market that companies in the medical and health industry would be able to capture this round of opportunities and boost their confidence to expand service scope and scale. Therefore, such a situation has brought significant float of AR. Despite the fact that there was a negative growth on the day of announcement, based on the significant growth during the days before and after, as well as the overall growth of $4.92 \%$ during the period of the event window with a confidence level of $1 \%$, it may be considered that the market showed cautious approval. As for the periods of $\left(\mathrm{T}_{-5}, \mathrm{~T}_{-1}\right),\left(\mathrm{T}_{-4}, \mathrm{~T}_{-1}\right),\left(\mathrm{T}_{-3}, \mathrm{~T}_{-1}\right)$ and $\left(\mathrm{T}_{-1}, \mathrm{~T}_{-1}\right)$, the average accumulative abnormal return reached $2.22 \%$ (the highest value of the four periods), with confidence levels of 5\%,5\%,10\% and 5\%. This suggests that there might be market expectations in a few days before the news was disclosed.

Although the impact of the Patient Protection and Affordable Care Act in America on the different sub-industry is not the same, but according to the research findings, it is to be positive on the hospital industry. (Hartley, 2012, and 
Borochin, \& Golec, 2016) Hartley (2012) found that average cumulative abnormal returns for hospitals sub-industry was $1.9 \%$ (1.6 billion dollars) on $\left(\mathrm{T}_{0}, \mathrm{~T}_{1}\right)$. On Chinese market, the value were $2.4 \%$ in 2009 and $1.53 \%$ in 2010 during the same period of $\left(\mathrm{T}_{0}, \mathrm{~T}_{1}\right)$. Despite the different percentage values, it shows that the medical and health care reform in China and the United States does have an effect on the medical listed companies.

Concerning the research limitations, the differences between analyzed companies and the influence what might be caused by small sample size are not discussed in this paper. And because China's stock market regulation is not complete enough, this might have some effect on the results. In addition, when explained how the market reacted to policies, it was incapable to prove the correctness of the reason analysis logically in consequence of capital market imperfections. Though the limitation of the dependence on securities market data led to the lack of empirical analysis in Chinese medical policy research, as one moves forward, it is expected that the analysis of the impact of medical policy will increase the number of listed hospital management companies. It will provide support to the development of the medical industry.

\section{Conclusion}

The result of empirical analysis shows that Chinese government's policy effectively encourages and guides civilian capitals to develop the medical industry. Meanwhile, Chinese medical and health industry are successfully stimulated as well. In this paper, much had been learned from the process of research based on the use of event study methodology. Consequently, the result of Chinese securities market reaction to the government's medical reform policies analyzed in this paper not only can proves the effectiveness of China's medical and health reform and the securities market, but also increases the applications of event study in the field of medical and health policies, thereby fills the gap in the empirical analysis of the effectiveness of China's medical policies on promoting private capital to invest in hospitals.

\section{Acknowledgement}

Competing interest statement: The author denies that he has any intention to obtain any financial interests.

\section{References}

Ababneh, M., \& Tang, A. (2013). Market reaction to health care law: an event study. International Journal of Accounting and Financial Reporting, 3, 108-127. https://doi.org/10.5296/ijafr.v3i1.3356

Binder, J. (1985). Measuring the effects of regulation with stock price data. Rand Journal of Economics, 16, 167-183. https://doi.org/10.2307/2555408

Borochin. P., \& Golec, J. (2016). Using options to measure the full value-effect of an event: application to Obamacare. Journal of Financial Economics, 120(1), 169-193. https://doi.org/10.1016/j.jfineco.2016.01.009

Cai, J. N. (2014). Analysis on policy characteristic and its impact on private medical industry. Health Economics Research, 10, 14-18.

Dnes, W. A., Kodwani, G. D., Seaton, S. J., \& Wood, D. (1998). The regulation of the United Kingdom electricity industry: an event study of price-capping measures. Journal of Regulatory Economics, 13, 207-226. https://doi.org/10.1023/A:1008027419553

Fama, F. E., Fisher, L., Jensen, C. M., \& Roll. (1969). The adjustment of stock prices to new information. International Economic Review, 10(1), 1-21. https://doi.org/10.2307/2525569

Hartley, J. (2012). Health care reform and health care stocks: evidence from the supreme court ruling. BFI Working Paper, Series No. 2012-009. https://doi.org/10.2139/ssrn.2111642

Kamae, H., \& Tetsuka, K. (2000). Market efficiency and the event study analysis for the regulatory. The Hitotsubashi Review, 5, 719-729.

Kong, L. D., Liu, G. E., Li, L., \& Wu, Z. A. (2013). Opportunities and challenges for private hospitals in the on-going health reform. Chinese Journal of Hospital Administration, 9, 641-645

Mackinlay, C. A. (1997). Event studies in economics and finance. Journal of Economic Literature, 3, 13-39.

Seiler, M. J. (2004). Performing financial studies: a methodological cookbook. Upper Saddle River, NJ: Prentice Hall.

Tang, J. X. (2016). The influence of monetary policy to asset price: based on the empirical research of the influence of Chinese monetary supply to house price and stock price. Value Engineering, 21, 25-28.

Zhang, J. F., Ren, C. Q., Jia, S. H., \& Yu, X. F. (2013). The effect of intervention policies on real estate market. China Soft Science, 1, 43-49.

Zhang, J. R., Liu, H., \& Hu, X. B. (2002). Valuation model based on more adequately used accounting information-the establishment and application of RIR model. Journal of Finance and Economics, 7, 68-74.

Zhang, Q. (2010). The application of event study to the evaluation of China's drug price reduction policies. Journal of Finance and Economics, 12, 4-15. 